\title{
Boquitas pintadas, una novela para armar. Primeras notas y borradores de un proyecto creativo en construcción
}

\section{Boquitas pintadas, a Novel to Make. First Notes and Drafts of a Creative Project in Progress}

\section{Resumen}

Este trabajo propone estudiar los documentos pre-textuales germinales y aquellos otros que permiten identificar los ajustes de obra más representativos del proceso de producción de la novela Boquitas pintadas del escritor argentino Manuel Puig. Estos materiales dan cuenta de las decisiones tendientes a formalizar y afinar un plan razonado de producción, opuesto al azar de una escritura improvisada. Además, permiten identificar ciertos hábitos en el modo de producción literaria iniciado en este plan y sostenido en el resto de la producción narrativa del autor. El trabajo también propone hacer foco en dos aspectos centrales a los que Puig no deja de atender desde el inicio de su planificación: la articulación entre el contenido del relato y la estructura compleja de la obra.

Palabras claves Boquitas pintadas, proceso creativo, pre-textos prerredaccionales, contenido, estructura

\begin{abstract}
This article proposes to study the pre-textual germinal documents and those that allow us to identify the most representative work settings of the production process of the novel Boquitas pintadas by the Argentinian writer Manuel Puig. These materials explain unfinished decisions for formalizing and sharping a reasoned plan of production, as opposed to an improvised writing. They also allow identifying certain habits in the literary production mode initiated in this plan and sustained in the rest of the author's narrative production. The article also proposes focusing on two central aspects which Puig attends from the beginning of his planning: the articulation between the plot and the complex structure of the novel.
\end{abstract}

Keywords 


\section{Sobre los inicios: génesis y creación}

Interesada por los manuscritos y demás borradores de obras literarias, la genética textual estudia los procesos creativos de escritores modernos concentrándose en la forma física del soporte, en los instrumentos utilizados por quienes escriben, en las huellas que deja el recorrido de un trazo, en los vaivenes que supone la mejor lección para lo que se pretende decir, en las apropiaciones, lecturas y relecturas que hacen los escritores de otras fuentes o de otros materiales. Sus posibilidades de estudio son numerosas y van desde el ordenamiento de un dossier de génesis a su edición, su análisis hermenéutico, su puesta en relación con otras áreas del universo escritural de un mismo autor, o de sus pares, de la forma en que ese proyecto fue mutando a través del tiempo (Grésillon 1994). Más allá de la singularidad de cada plan de trabajo, en la perspectiva de los estudios de génesis prevalece la concepción de la escritura como un acto en movimiento y del texto como un objeto mutable y dinámico (Grésillon 1994; Lois 2001). Esto puede verse tan solo en el registro de un mínimo segmento escritural de preparación de obra y en las reescrituras, tachaduras y correcciones que supone la sola elección de una línea de texto, movimiento que no acaba en la preparación del manuscrito, sino que puede extenderse a las distintas fases pre-textuales, es decir, a otros estadios previos a la publicación, así como también a la fase textual, momento en que el texto publicado puede adquirir nuevos cambios en sus distintas ediciones, reimpresiones o adaptaciones (De Biasi 2008; Colla 2010). 
CATEDRAL TOMADA: Revista de crítica literaria latinoamericana / Journal of Latin American Literary Criticism Boquitas pintadas, una novela para armar. Primeras notas y borradores de un proyecto creativo en construcción

En una novela como Boquitas pintadas de Manuel Puig, importa hacer foco en esta cuestión ya que en el archivo personal del escritor ${ }^{1}$ se resguarda gran parte de la documentación que permite analizar y establecer conjeturas sobre un plan de obra, sobre el establecimiento de las decisiones autorales de construcción narrativa o sobre sus movimientos y reescrituras. Casi todo el material pre-textual, desde pequeños diagramas de planificación hasta distintas versiones de redacción en manuscritos y mecanogramas, y de material textual, en las distintas ediciones de la novela, son resguardados en su archivo junto con el material perteneciente a otros proyectos de su producción. ${ }^{2}$ Esto permite realizar un estudio exhaustivo de los movimientos que registran estas decisiones en los pre-textos y en los textos, ${ }^{3} \mathrm{y}$ también proponer un estudio centrado en un momento particular de ese proceso, como se pretende en este artículo.

La novela Boquitas pintadas fue publicada en 1969 en la ciudad de Buenos Aires por el sello Sudamericana, la misma casa editorial que había publicado uno de los libros más representativos del boom de la literatura latinoamericana, Cien años de soledad de Gabriel García Márquez (1967). Puig comienza a delinear los primeros planes para su obra en 1967, apenas un año antes de que saliera a la luz su primera novela, La traición de Rita Hayworth (1968). No está de más recordar en este punto el famoso "accidente" que da origen a ese primer trabajo y que lo inicia en la literatura (Giordano 1996). El mismo Puig rememoró en más de una ocasión ese comienzo azaroso y circunstancial en el que intentaba escribir un guión como ejercicio para sus estudios de cine y terminó dando forma a una voz que no paraba de hablar. ${ }^{4}$ La palabra fluyó a borbotones para desbordar el espacio limitado

${ }^{1}$ La reproducción digital de los documentos del Archivo Manuel Puig puede consultarse en línea en: arcas.fahce.unlp.edu.ar/arcas/portada/colecciones/manuel-puig. Cada vez que en este trabajo se analice un documento existente en ese archivo, se citará su referencia exacta para facilitar la consulta en la web.

2 Agradezco la gentileza del Sr. Carlos Puig, heredero y custodio de la obra de su hermano, por permitirme consultar el archivo del escritor.

${ }^{3}$ Este trabajo ha sido realizado en la tesis doctoral Edición crítico-genética de Boquitas pintadas. Folletín (1969) de Manuel Puig (Rodas inédito) presentada y defendida en la Universidad Nacional de La Plata en el año 2015.

${ }^{4}$ Así lo rememora el autor: "Yo no decidí pasar del cine a la novela. Estaba planeando una escena de guión en que la voz de una tía mía, en off, introducía la acción en el lavadero de una casa de 
que ofrecía la forma del guión y siguió contando un relato incontenible que ocupó las hojas suculentas de su primera novela. Un origen diferente cuenta Boquitas pintadas, pensada inicialmente para ser difundida por entregas como un folletín. Lejos de esa aspiración, pero conservando la estructura, la novela adquirió el formato libro y, a diferencia de lo que había ocurrido con la respuesta de la crítica literaria local en su experiencia con el caso anterior, resultó un éxito que consagró a Manuel Puig como escritor profesional.

En conjunto, La traición de Rita Hayworth y Boquitas pintadas, forman parte del ciclo de Coronel Vallejos en el contexto de la producción de Puig. Ese lugar ficticio, donde se sitúan los acontecimientos tiene como punto de referencia a General Villegas, ${ }^{5}$ ciudad natal del autor. La primera de ellas hace de Toto (CocoPuig) un protagonista central bajo la forma de la ficción autobiográfica. La segunda pone el acento en un grupo de personajes típicos de la clase media pueblerina durante los años 30 y 40, en sus deseos y conflictos amorosos, en los desplazamientos sociales y económicos que transitan y en las consecuencias que les acarrean sus recorridos: la joven que anhela una vida mejor (Nené), la mala de buena familia (Mabel), la sirvienta (Rabadilla), el galán que enamora a todas (Juan Carlos), el joven marginal en leve ascenso social (Pancho), la hermana celosa y solterona (Celina) y la viuda que cree en una segunda oportunidad (Elsa di Carlo).

En este trabajo se propone estudiar los documentos pre-textuales germinales y aquellos otros que dan cuenta de los ajustes de obra más representativos del proceso de producción de Boquitas pintadas haciendo hincapié en su modo de composición y en el proceso genético, tema singular sobre el que no existen estudios previos. Esto se refiere exactamente a los planes, esquemas y bosquejos que dan cuenta de las decisiones tendientes a formalizar y afinar un plan razonado

pueblo. Esa voz tenía que abarcar no más de tres líneas de guión, pero siguió sin parar unas treinta páginas. No hubo modo de hacerla callar. Ella sólo tenía banalidades para contar; pero me pareció que la acumulación de las banalidades daba un significado especial a la exposición" (Puig 1985 10).

${ }^{5}$ El Partido de General Villegas se encuentra situado en el extremo noroeste de la provincia de Buenos Aires, a 465 kilómetros de la Capital Federal. Cuenta con una población de 18.275 habitantes (Instituto Nacional de Estadística y Censos, 2010). 
CATEDRAL TOMADA: Revista de crítica literaria latinoamericana / Journal of Latin American Literary Criticism Boquitas pintadas, una novela para armar. Primeras notas y borradores de un proyecto creativo en construcción

de creación, opuesto al azar de una escritura improvisada con miras a identificar, por un lado, ciertos hábitos en el modus scribendi de este autor, que consideramos iniciados en este plan y luego sostenidos en el resto de su producción literaria. Este trabajo también propone detallar dos aspectos a los que Puig atiende desde el inicio de su planificación. Por un lado, un contenido muy decidido del relato, inspirado en el pasado propio, en una historia de vida que sirve a la creación. Por otro lado, los criterios que guían la elección de un formato de obra, y la importancia que adquiere en tal sentido la referencia a ciertos objetos como soportes materiales y simbólicos, que van a dar con la estructura particular de esta novela, elemento central que ha justificado su lectura como obra literaria de arte pop (Lavers 1988; Lorenzo-Alcalá 1990; Páez 1995; Giordano 2001; Speranza 2003). Como hipótesis, entendemos que en este proyecto Puig se esfuerza por objetivar el relato ensayando distintas técnicas narrativas y por el programa estructural de la novela con la finalidad de dar solidez y coherencia a la forma. De acuerdo con la lectura de los prerredaccionales, esto lo realiza en la construcción de los personajes partiendo de modelos referenciales realistas y estereotipados que se van puliendo y modelando para profundizar su ficcionalización a través de distintos procedimientos. Los prerredaccionales también muestran cómo se va construyendo la macroestructura que hace al conjunto de la obra conteniendo microestructuras discursivas que aportan sentidos suplementarios a la construcción de los personajes y de sus voces. Además, documentan el tratamiento particular del tiempo, representado en base a cortes y quiebres continuos, un aspecto elaborado en forma paralela y en función de los personajes, de los tipos discursivos y del armado de una trama en la que deben coincidir las partes de la historia desperdigada. De todo ello, entendemos que los manuscritos prerredaccionales pueden leerse como testimonios de toda una estructura subterránea que es la base de la novela, como el inicio de un proceso que seguirá la vía de la textualización en un adelgazamiento y alejamiento progresivo de lo referencial y de las estructuras y técnicas más próximas a la narrativa tradicional, en función de una mayor experimentación literaria y complejidad en la novela. 


\section{Sobre el contenido: germen para un relato}

Puig se refiere a la idea original para Boquitas pintadas en una entrevista con Saúl Sosnowski publicada en la revista Hispamérica (1973) en la que señala los puntos de contacto y de ruptura con respecto a La traición de Rita Hayworth (1968):

La primera novela era un intento de comprender por qué habían sucedido ciertas cosas; estaba todo centrado en mí como chico, después como adolescente. Los personajes de la novela son gente que había compartido algo conmigo en aquella época. Gente que había tenido muy cerca; familiares, vecinos [...] De esa gente me animé a escribir porque los conocía más, habían estado más cerca de mí, porque me habían dedicado tiempo. Pero quedaban en el tintero toda una cantidad de personajes de ese pueblo. Los que habían aceptado las reglas del juego, los que estaban en el 'establishment', las 'miss primavera', los profesionales [...] Terminada Rita Hayworth volví a la Argentina, en el año 67, y encontré después de muchos años a aquellos protagonistas, a esos integrados a la sociedad que me habían impresionado tanto [...] Al ver el punto de llegada de esta gente, toda muy frustrada, me animé a intentar escribir una novela, una interpretación de los hechos que me habían llenado de maravilla..., de esa gente que había creído en los cánones de una época, que habían aceptado las reglas del juego y les había ido, por lo general, muy mal. Boquitas pintadas es un intento de comprender a esta gente en base a datos que recogí al volver a mi país después de once años fuera. (73-74) 
CATEDRAL TOMADA: Revista de crítica literaria latinoamericana / Journal of Latin American Literary Criticism Boquitas pintadas, una novela para armar. Primeras notas y borradores de un proyecto creativo en construcción

Los pre-textos prerredaccionales ${ }^{6}$ que se estudian en este trabajo se encuentran rotulados en el archivo del escritor como N.B.1.Grupo 1 y N.B.2.Grupo 2. ${ }^{7}$ Temporalmente pueden datarse en el período que se inicia en 1967, etapa inaugural del proyecto Boquitas pintadas, que se extiende por lo menos hasta 1968, mismo año de redacción de la novela escrita en Buenos Aires. Es probable que más allá de las declaraciones que el autor realiza en la entrevista con Sosnowski algunas notas provisorias hayan sido tomadas mientras Puig vivía en la ciudad de Nueva York (1963-1967). Una razón para considerar esta posibilidad es que el autor escribe sobre el vuelto de hojas mimeografiadas de Air France, la compañía aérea en la que fue empleado durante los años de su residencia neoyorquina. Además, hacia la izquierda de uno de los documentos que forman parte del conjunto (N.B.2.0036r $)^{8}$ anota una lista de regalos que planeaba enviar a su familia en Buenos Aires, actividad que realizaba regularmente cuando se encontraba en el exterior, como lo revelan sus cartas publicadas póstumamente (Puig 2005, 2006). ${ }^{9}$

En cuanto a la forma de composición y del análisis de los pre-textos prerredaccionales deducimos que el escritor cuenta con un argumento definido al iniciar su proyecto creador y acotado a la representación de los personajes que planea incorporar, en coincidencia con lo que relata en la entrevista con Sosnowski. Luego se puede observar que traza una estructura para contar cada capítulo y cada episodio del modo más conveniente conforme al programa general. En el trayecto de la redacción se advierte que esos planes se ajustan con el agregado de nuevos

${ }^{6} \mathrm{Si}$ bien se analizan materiales de tipo prerredaccional, fase de la génesis que señala un momento exploratorio y de programaciones previas a la textualización (Lois 2), ello no significa que el total de la documentación sea temporalmente anterior a la redacción de la novela, sino que se trata de bosquejos, planes y diagramas de ideas embrionarias y de reajustes de la obra correspondientes a distintas fases del trabajo creativo.

${ }^{7}$ Pueden consultarse en el siguiente enlace: arcas.fahce.unlp.edu.ar/greenstone3/library/collection/puig/browse/CL1\#CL1.1,CL1.1.2,CL1.1.2.3

${ }^{8}$ Ver en: arcas.fahce.unlp.edu.ar/greenstone3/sites/localsite/collect/puig/index/assoc/puigNBpN/B020033-.dir/boquitaspintadas0036r.jpg

${ }^{9}$ Por ejemplo, en carta del 7 de octubre de 1961 desde Roma, Puig escribe: "El otro día pasé por una liquidación y les compré dos cosas que estaban a menos de la mitad, una camisa sport blanca para papá y una remera de rafia que puede ser para hombre o mujer, pero me parece muy llamativa para Buenos Aires (para hombre digo) así que podría ser para vos mamá [...] La camisa blanca es hermosa, de seda de nylon, yo me compré otra para mí, manga larga" (2005 279). 
episodios o con variaciones sobre los ya esquematizados e incorpora materiales que inicialmente no habían sido considerados. Un primer vistazo sobre estos manuscritos también permite conjeturar que el escritor trabaja para acomodar el contenido de la novela y se ocupa de organizar y sobre todo complejizar su estructuración, como desarrollaremos a continuación.

Uno de los primeros esbozos sobre el argumento de la novela se encuentra en el manuscrito N.B.2.0071r, ${ }^{10}$ en el cual leemos un plan definido sobre el tema general, el contenido y las funciones de los protagonistas. Se trata de uno de los pocos testimonios en el cual los personajes de Nené y Celina aparecen como Chola y Marina, nombres previos a los de su fijación textual, razón para conjeturar su escritura en una etapa muy inicial del proyecto, debido a que esas figuras se incorporan a la primera fase de textualización con sus nombres definitivos, como Nené y Celina. ${ }^{11}$ Podríamos conjeturar que esto ocurre ya que se pretende borrar desde este momento inicial de composición algún tipo de referencia biográfica, cuestión que también se observa en otros casos ya más avanzado el proyecto escritural, como se irá advirtiendo en los próximos apartados.

No obstante, en el testimonio también se mencionan otros personajes con el nombre de su referente biográfico, habitantes de General Villegas, que fueron fuente de inspiración para esta novela y que conservarán esos nombres durante buena parte del proceso redaccional. En este sentido interesa la referencia a Danilo, protagonista masculino cuya reescritura muta al nombre de Juan Carlos. El personaje está inspirado en Danilo Bernardo Caravera, un villeguense fallecido a los treinta y un años de edad debido a una larga enfermedad (Rodas 2011). ${ }^{12}$ Puig

\footnotetext{
${ }^{10}$ Ver en: arcas.fahce.unlp.edu.ar/greenstone3/sites/localsite/collect/puig/index/assoc/puigNBpN/B020033-.dir/boquitaspintadas0071r.jpg

${ }^{11} \mathrm{La}$ única variante con respecto a este nombre es que en las primeras etapas de composición el autor lo escribe como Selina.

${ }^{12}$ El primer capítulo de la novela se inicia con la necrológica de Juan Carlos aparecida en la revista ficticia titulada Nuestra Vecindad. En su edición del 30 de diciembre de 1943, el diario La Idea de General Villegas emite la necrológica dedicada a la muerte de Danilo Bernardo Caravera. Agradezco este dato y la copia del texto a Patricia Bargero, estudiosa e impulsora de la obra de Manuel Puig.
} 
CATEDRAL TOMADA: Revista de crítica literaria latinoamericana / Journal of Latin American Literary Criticism Boquitas pintadas, una novela para armar. Primeras notas y borradores de un proyecto creativo en construcción

relata la impresión que le causó este joven cuando lo conoció en una reunión de señoras:

Había en Villegas, mi pueblo, un muchacho que tenía entre 20 y 30 años, muy bien parecido, de aspecto siempre cuidado, que no trabajaba. La primera vez que llamó mi atención fue en un té de señoras, donde él era el único hombre [...] Fue muy cariñoso conmigo. Cuando volvimos a casa, mamá me frotó con alcohol. Me explicó que ese muchacho estaba tuberculoso, que tenía poco tiempo de vida. Fue una impresión terrible, porque el aspecto físico no hacía sospechar nada. Se llamaba Danilo, un hombre de película [...] Al poco tiempo, Danilo murió. Fue muy llorado porque era una persona plácida, de buen carácter. (Rodríguez Monegal 56)

Según el mismo autor, Danilo no fue el único referente para la creación de Juan Carlos, un personaje poco empático, vividor, desdeñoso y seductor como el mítico Don Juan, señal que desnuda la conexión entre los nombres, y que al mismo tiempo descubre en la reescritura cierto menosprecio por Danilo y un gran interés literario por el libertino:

Años después asocié a Danilo con otro muchacho, desocupado también, pero no por enfermedad, sino por inadaptación al medio [...] Se le parecía mucho físicamente. Éste era un resentido malhumorado, de familia venida a menos. Don Juan implacable. Al escribir la novela fundí ambas figuras en una; de Danilo sólo retuve la extraordinaria apostura física, y la enfermedad. Todos los defectos son del otro. (Rodríguez Monegal 56)

En el testimonio que se analiza (N.B.2.0071r) también se apuntan decisiones sobre el hilo medular del relato que pasarán a la instancia de textualización, entre las que se cuentan: la muerte de Juan Carlos y el envío de 
cartas por parte de Nené a la madre del difunto; ${ }^{13}$ la referencia a su estado de insatisfacción constante, rayano al bovarismo, debido a la pérdida de su antiguo amor y la infelicidad de su matrimonio actual; su odio hacia Celina, hermana de Juan Carlos, como culpable de su amor frustrado; ${ }^{14}$ la necesidad de Celina de vengarse por considerar a Nené responsable de la muerte de su hermano y su ímpetu por poner al descubierto el fracaso matrimonial de Nené. ${ }^{15}$ Es interesante que cuando Puig se refiere a este último personaje, no lo hace solo con el nombre Chola, sino que prima la alusión a su estado civil, "la casada", forma que destaca el vínculo marital, causa de la frustración que moviliza su recorrido en la novela. Esto revela a través de los manuscritos la estructura subterránea de la novela construida en base a estereotipos que han sido individualizados, un gesto coherente con el de encubrir los referentes realistas y el material biográfico, visible en las reescrituras de los nombres y en las decisiones tendientes a la experimentación literaria sobre materiales preexistentes.

Sumado a lo anterior, en el documento también se declaran algunos episodios puntuales, como la tirada de cartas a Juan Carlos, ${ }^{16}$ que se desarrolla en la sexta entrega; el encuentro entre Nené y la viuda Elsa di Carlo (Dora Fernández en esta instancia) en Córdoba, ${ }^{17}$ episodio que se relata en la entrega decimoquinta, y la incorporación del personaje de Rabadilla, mencionada como "la sirvienta". ${ }^{18}$

Las notas inscriptas en el manuscrito también prueban que ya desde este momento se programan algunas formas textuales a través de las cuales se contará el relato, como por ejemplo, el género epistolar y otros frecuentes en la prensa periódica de la época en que se ambienta la novela, como la nota necrológica y la crónica del día de la primavera, tipos textuales que junto con otros incorporados

\footnotetext{
13 "La casada lee noticia fúnebre y escribe carta a la madre de Danilo" (N.B.2.0071r).

14 "Lo que mueve todo es el odio de Chola a la hermana de Danilo, que fue quien le arruinó el pastel" (N.B.2.0071r).

15 "Chola pasa por mujer feliz y lo que quiere Marina es deschavarla que no lo es" (N.B.2.0071r).

16 “Alguien (una mujer) le tira las cartas a Danilo” (N.B.2.0071r).

17 "Se encuentra con la Dora Fernández para que le cuente de Danilo en Córdoba. Versión opaca de la vida de Danilo con una mujer que se le parece espeluznantemente, una frustrada, casada (posiblemente una que acompañó marido a Cosquín y se le murió)" (N.B.2.0071r).

18 “Trabajar sobre relación con sirvienta, relación Muni-Negrita” (N.B.2.0071r).
} 
CATEDRAL TOMADA: Revista de crítica literaria latinoamericana / Journal of Latin American Literary Criticism Boquitas pintadas, una novela para armar. Primeras notas y borradores de un proyecto creativo en construcción

más tarde e hilvanados entre sí conforman la estructura orgánica, ensamblada y compleja de esta obra, como se desarrollará luego.

\section{Sobre los personajes: deslindes y ajustes para un argumento decidido}

En los pre-textos prerredaccionales también se insiste en la construcción semántica de los personajes. Al igual que se veía en el testimonio previo, se anotan nuevos referentes biográficos, otros vecinos del partido bonaerense de General Villegas, como sucede en el manuscrito N.B.2.0036r, ${ }^{19}$ en el cual se apuntan algunos nombres que fueron tachados ${ }^{20}$ como las Compagnucci, Muni Seró, María, Mouras y Cleofé, y otros sin tachar como Darío Caravera, Dora Fernández, Rosita Nevares, las Méndez, los Ibañez, Baby Ortea, los mellizos Barrios, la Pela, la hermana de la Pela, la de Palomino y el asesinado, las Bogliolo, Eguy y Navarro el oficial. Como puede verse, el programa de composición supone una cantidad notable de referentes considerados por el escritor, aunque no todos ellos pasarán a la etapa de redacción y, en otros casos, se van a fusionar entre sí para construir un solo personaje como se verá luego para el caso del policía Pancho.

A pesar de que en esta instancia de anotaciones aún se encuentran en estado embrionario, las figuras adquieren sus rasgos distintivos más sobresalientes y se registran las funciones textuales que van a desempeñar, como se revela en el documento N.B.2.0055r, ${ }^{21}$ en el cual el escritor anota una lista de los protagonistas acompañados de alguna frase descriptiva dispuesta a acotar su rol semántico o su identificación textual más sobresaliente. ${ }^{22}$ Para Nélida, por ejemplo, apunta

\footnotetext{
${ }^{19}$ Ver en: arcas.fahce.unlp.edu.ar/greenstone3/sites/localsite/collect/puig/index/assoc/puigNBpN/B020033-.dir/boquitaspintadas0036r.jpg

${ }^{20}$ Algunos de ellos fueron identificados por Carlos Puig, hermano del escritor, como vecinos de General Villegas en una entrevista que le realizamos en el mes de marzo de 2010. Entre ellos, las Compagnucci, Darío Caravera, Rosita Nevares, las Méndez, la de Palomino y la de Ferro.

${ }^{21}$ Ver en: arcas.fahce.unlp.edu.ar/greenstone3/sites/localsite/collect/puig/index/assoc/puigNBpN/B020033-.dir/boquitaspintadas0055r.jpg

${ }^{22}$ Los personajes que se listan son: Nélida, Danilo (cuyo nombre mutará por el de Juan Carlos), Mila (que será llamada Mabel), Marido (de Nené), Marina (que cambiará por Celina), Pela (que
} 
"nostalgia romántica", frase que sintetiza su añoranza por el tiempo feliz en que pudo conocer "la belleza de la vida" en su relación con Juan Carlos. El fracaso amoroso del pasado y la desilusión en el presente de Nené justifican que para el caso de su marido, Puig anote "triunfa y para qué", en referencia a su éxito laboral y su fracaso marital. Para Celina, Marina en esta instancia, anota "no logra casarse", en alusión al peso familiar y social que debe soportar debido a su soltería. Por su parte, Rabadilla, Pela en este documento, recibe la nota "llegar última", debido al ascenso que transita este personaje de sirvienta a dueña de su propia finca. Rabadilla "llega [o ríe] última", pero "llega [o ríe] mejor" porque se fortalece y logra progresar en su posición económica y social. ${ }^{23}$

A propósito de Mabel (o Mila), Puig anota "el desbarranque" en alusión a la desgracia que atraviesa debido al negocio fraudulento que comete su padre y conduce a su familia de clase media alta a la quiebra. Por su parte, la viuda di Carlo, Dora en este manuscrito, se identifica con la frase "calma burrez", por tratarse de un personaje imprudente que delega su decadente economía al desmedido Juan Carlos. Otras dos figuras masculinas son mencionadas en el esquema, Roberto y Barrios, quienes van a confluir en la construcción de Pancho. Del primero se anota "paralelo masculino de Mila", en referencia al carácter lujurioso que comparte con Mabel y que los encuentra como amantes secretos. Del segundo se anota "la agresión”, en alusión a la violencia que hace de Pancho un ser peligroso para Mabel y un compañero tosco y rudo para Rabadilla (Rodas 2011).

En la misma línea, en la parte inferior del manuscrito N.B.2.0073r ${ }^{24}$ se presenta un esquema sobre las relaciones que se establecen entre los personajes, aún con nombres correspondientes a las primeras etapas de composición. Se

llevará el apodo de Raba), Dora (viuda di Carlo) y Roberto y Barrios (probablemente la combinación de ambos haya derivado en la construcción de Pancho).

${ }^{23}$ Dice Roxana Páez: "Los personajes extremos femeninos tienen 'cierres' obvios en Boquitas pintadas. Mabel fracasó en la posibilidad matrimonial que la hubiera convertido en estanciera y el final la muestra con un nieto paralítico. La Raba formó una gran familia y se autoabastece. Su imagen final en el carro, llevando provisiones a sus hijos, es épica (al estilo de Lo que el viento se llevó)" (25).

${ }^{24}$ Ver en: arcas.fahce.unlp.edu.ar/greenstone3/sites/localsite/collect/puig/index/assoc/puigNBpN/B020033-.dir/boquitaspintadas0073r.jpg 
CATEDRAL TOMADA: Revista de crítica literaria latinoamericana / Journal of Latin American Literary Criticism Boquitas pintadas, una novela para armar. Primeras notas y borradores de un proyecto creativo en construcción

observan dos zonas claramente diferenciadas: a la izquierda se dibuja un esquema arbóreo encabezado por la referencia "mujeres" desde donde descienden cinco líneas que culminan en los nombres de Chola (Nené), Mila (Mabel), la de Pinto (otro referente biográfico para Rabadilla), Dora Fernández (Elsa di Carlo) y la fórmula "una maestra rea", personaje que se programa en esta instancia pero que no pasa a la etapa de textualización, al igual que la idea que se apunta como posibilidad de insertar otra amante para Juan Carlos (“¿una mujer casada más? Sí, una platónica como la viuda"). Hacia la derecha se bosqueja un cuadro de equivalente función para los hombres, cuyas ramas culminan en las siguientes indicaciones: Danilo (Juan Carlos), algún médico (Aschero) y otras tres referencias que confluirán en la construcción de Pancho: "Navarro el oficial", "los mellizos Barrios" y "Roberto combinado con Baby Ortea". Por medio de líneas punteadas se señalan las relaciones íntimas que se van a desarrollar entre los personajes. Por ejemplo, la línea de puntos de Juan Carlos (Danilo) se proyecta hacia Nené (Chola), hacia la viuda (Dora Fernández) y hacia la inscripción que sugiere la posibilidad de otra amante ("una platónica como la viuda").

En el documento también parecen programarse otros hilos argumentales, por ejemplo, la línea de puntos que sigue la referencia "algún médico" se extiende hacia "una maestra rea" y Dora Fernández. Sin embargo, en la novela ese plan no se concreta, ya que el doctor Aschero tiene una relación clandestina con Nené, en lugar de las mujeres que se apuntan en el manuscrito. Algo similar ocurre con los mellizos Barrios, Roberto y Navarro el oficial, cuyas líneas se dispersan hacia Mila y "la de Pinto", lo que lleva a conjeturar que esos hombres pudieron confluir en el policía Pancho, único protagonista que mantiene relaciones con Rabadilla y Mabel, personajes en los que derivan esas mujeres. Lo que este documento permite leer entonces es un esbozo inicial que contempla una mayor interacción entre las figuras y otras líneas de la trama que se suprimen o reducen en el programa de escritura.

Una instancia de planificación más avanzada se conserva en documentos que sintetizan las relaciones entre los personajes con definiciones más precisas 
sobre el argumento, como ocurre en N.B.1.0009v. ${ }^{25}$ A pesar de que esta etapa continúa siendo de organización y construcción de la historia, donde todavía permean expresiones vacilantes en forma de interrogaciones ("Selina los hace dejar, ¿él visita de noche a Mila?” o “¿Pela va a Bs. As. a ayudar a Nené?”, N.B.1.0009v) es notable el avance en la delimitación del contenido.

En el manuscrito N.B.1.0009v se observa una planificación muy similar a la que desarrolla la novela. Al trayecto de los protagonistas, que en esta instancia muestra detalles concretos sobre episodios puntuales, se suman referencias sobre personajes secundarios como el padre de Mabel y el joven estanciero, su pretendiente. ${ }^{26}$ Siguiendo cada fila del documento, se precisa: 1) La amistad que une a Juan Carlos (Danilo) con Pancho (Roberto-Barrios); ${ }^{27}$ 2) La relación clandestina entre Juan Carlos y Mabel (Mila); ${ }^{28}$ 3) La ruptura de ese vínculo por oposición del padre de Mabel y el estanciero inglés como posible pretendiente ${ }^{29} 4$ ) El pasado amoroso con el Dr. Aschero que le impide a Nené concretar su relación con Juan Carlos; ${ }^{30}$ 5) La interposición de Celina como obstáculo entre Nené y Juan Carlos, y el enlace de Nené con otro hombre; ${ }^{31}$ 6) La enfermedad de Juan Carlos y la maternidad de Rabadilla (Pela); ${ }^{32} 7$ ) El viaje de Raba a Buenos Aires; ${ }^{33}$ 8) El asesinato de Pancho (Barrios) en manos de la sirvienta y su alianza secreta con Mabel; ${ }^{34}$ 9) La ruptura de Mabel con el pretendiente inglés; ${ }^{35}$ 10) La muerte de Juan Carlos y; 11) El éxito final de Celina en la revelación del fracaso matrimonial de Nené. ${ }^{36}$

\footnotetext{
${ }^{25}$ Ver en: arcas.fahce.unlp.edu.ar/greenstone3/sites/localsite/collect/puig/index/assoc/puigNBpN/B010001-.dir/boquitaspintadas0009v.jpg

26 "Padre Mila los hace dejar" y "se vislumbra inglés estanciero" (N.B.1.0009v).

27 "Danilo - Roberto y Barrios íntimos" (N.B.1.0009v).

28 "Danilo novio de Mila (coje secret[amente])" (N.B.1.0009v).

29 "Padre Mila los hace dejar" (N.B.1.0009v).

30 "Danilo y Nené, ella no se deja porque él se daría cuenta de ausencia virgo ascheriado" (N.B.1.0009v).

31 "Selina los hace dejar, ¿él visita de noche a Mila?" y "Nené se casa" (N.B.1.0009v).

32 "Danilo enfermo y Pela tiene hijo de Barrios" (N.B.1.0009v).

33 "Pela va a Bs. As. [i] a ayudar a Nené?" (N.B.1.0009v).

34 "Vuelve Pela y mata a Barrios" y "no se sabe nada que Mila participó" (N.B.1.0009v).

35 “(se desvanece estanciero)" (N.B.1.0009v).

36 "Muere Danilo" y "Selina logra hacer confesar a Nené que no es feliz con su marido" (N.B.1.0009v).
} 
CATEDRAL TOMADA: Revista de crítica literaria latinoamericana / Journal of Latin American Literary Criticism Boquitas pintadas, una novela para armar. Primeras notas y borradores de un proyecto creativo en construcción

La inscripción "Pela - Líber”, que se resalta en el manuscrito con letras de mayor tamaño respecto del resto de las escrituras, se interpreta en relación con la admiración que siente Rabadilla (Pela) hacia la famosa actriz y cantante de tangos argentina, Libertad Lamarque (1908-2000), que inspira a Raba a imitar su voz, ir al cine o pensar críticamente en el amor, en las diferencias sociales y en la traición (Giordano 2001: 122; Rodas 2012). Esto también demuestra la búsqueda del autor sobre modelos preexistentes y referentes externos al universo textual, muchas veces biográficos, para la construcción semántica de las figuras que recrea.

\section{Sobre la estructura: plan para géneros discursivos y formas textuales}

Siguiendo con el plan formal de la novela, desde las primeras etapas se deduce el interés por contar el relato a través de distintos tipos de textos y géneros discursivos, como lo demuestra uno de los papeles más primitivos que se conservan sobre el proceso de escritura, N.B.1.0025. ${ }^{37}$

En el documento se dibujan pequeños recuadros que contienen la indicación de los distintos tipos textuales que van a componer la arquitectura de la novela, aunque en esa instancia no están completamente sistematizados de acuerdo con el orden que ocuparán en el texto publicado. En este momento, el esquema dibuja en forma de mapa un programa mental incipiente cuyas coincidencias con el orden estructural de redacción corresponden sólo con lo que se bosqueja al inicio, exactamente en la primera columna de la izquierda del cuadro, donde aparecen señaladas la nota necrológica, las primeras cartas de Nené a Leonor y la crónica del día de la primavera ("nota fúnebre", "carta Chola a vieja", "nota baile social" y "más cartas Chola"). El resto de las ideas apuntadas se irá acomodando de manera muy diferente, por ejemplo, las inscripciones en la lápida de Juan Carlos, que se anuncian en la primera columna ("inscripciones tumba Danilo"), se podrán leer

\footnotetext{
${ }^{37}$ Ver en: arcas.fahce.unlp.edu.ar/greenstone3/sites/localsite/collect/puig/index/assoc/puigNBpN/B010001-.dir/boquitaspintadas0025.jpg
} 
recién en el capítulo catorce de la novela, al igual que ocurre con la confesión de Mabel, que se anota en la parte inferior de la segunda columna ("confesión textual al cura").

En cuanto a los tipos textuales que se indican en el manuscrito, algunos efectivamente se trasladan a la obra, como la nota necrológica ("nota fúnebre"), la correspondencia que mantienen distintos personajes ("carta Chola a vieja" y "Danilo-Chola"), la crónica del día de la primavera cuando Nené es elegida reina ("nota social baile primavera"), los epitafios en honor a Juan Carlos ("inscripciones tumba Danilo"), las actas de la Policía de la Provincia de Buenos Aires sobre el ingreso de Pancho a la fuerza, y luego sobre su asesinato ("alguna parte del archivo de la comisaría"), la confesión de Mabel acerca de su complicidad en esa muerte, y las plegarias que emiten las mujeres por el fallecimiento del galán tísico ("algún rezo o confesión textual al cura"). También se leen las páginas de la agenda del protagonista masculino ("agenda de Danilo o Aguerre"), las consultas de Mabel a la revista femenina (“correo del corazón”), la emisión del folletín que escuchan Nené y Mabel ("alguien recomienda a otra una radionovela y como ya está empezada debe contarle el principio") y la descripción del álbum de fotografías de Juan Carlos ("descripción de una colección de fotos"). Se consideran también otras formas textuales que finalmente no serán incorporadas al plan redaccional. Esto se lee, por ejemplo, en las notas que anuncian el libro de cuentas de la casa de Mabel ("cuaderno de gastos de la casa de Mila"), la receta de cocina ("¿receta de cocina?") o el reportaje a algún protagonista del folletín ("reportaje en revista a alguien de la radionovela").

En ese bosquejo, la intervención de los personajes se programa en función de distintos medios textuales que permiten dar cuenta de su interioridad, como las cartas o la agenda, y de formas discursivas que objetivan el relato, por ejemplo, las inscripciones en la lápida de Juan Carlos o los informes del archivo de la policía, que permiten un distanciamiento con respecto a lo enunciado, voces que Josefina Ludmer ha analizado minuciosamente (15-16). Puede agregarse a esto que el soporte material que se representa (notas de la prensa periódica, informes médicos, 
CATEDRAL TOMADA: Revista de crítica literaria latinoamericana / Journal of Latin American Literary Criticism Boquitas pintadas, una novela para armar. Primeras notas y borradores de un proyecto creativo en construcción

cartas) cobra una dimensión fundamental para la voz que contiene y para aquello que se enuncia. Si el autor se preocupa por lograr una macroestructura sólida, una forma arquitectónica consistente para la integridad de la novela, también se ocupa de que cada parte destaque como microestructura que aporta sentidos suplementarios al enunciado como prueba documental que contribuye a la verosimilitud del relato.

En el manuscrito N.B.2.0041r $\mathrm{r}^{38}$ se programa la macroestructura en un listado minucioso de los tipos y formas discursivas que se integran en la obra de forma más ordenada y sistematizada que en el cuadro que se analizaba anteriormente. Allí se mencionan las cartas, un reportaje que luego se decide por una crónica, la agenda, el parte del archivo de la comisaría, los epitafios, la confesión, la radionovela, un informe médico y los diálogos telefónicos, entre otros. Es notable el orden estructural muy semejante al que posee la novela publicada, por lo menos hasta la mención del episodio en que Nené y Mabel escuchan la radionovela que se lee en el texto un poco antes de la ubicación que se le ha dado en el esquema, ya que se introduce en el capítulo trece, antes de los epitafios en la lápida de Juan Carlos, a diferencia de lo que exhibe el documento. Por otra parte, las anotaciones que vienen a continuación bosquejan ideas sobre distintos episodios (“escándalo Marina”, "versión objetiva Dora”) sin profundizar en los géneros que van a estructurar estas secciones, excepto en algunos pocos casos, como en la indicación "cartas Nélida". De todo lo expuesto se deduce que, al momento de realizar este esquema, la redacción de al menos el primer tercio de la novela ya estaba avanzado o más decidido que el resto del proyecto escritural, que contará con la mayor cantidad de modificaciones.

En el documento de obra que se viene analizado (N.B.2.0041r), al igual que se señalaba para el caso del testimonio N.B.1.0025, también se anotan técnicas narrativas que se proyecta poner en práctica, sobre todo aquellas que apuntan a objetivar el relato, por ejemplo, “trozos escritos por objetos”, “descripción objetiva

\footnotetext{
${ }^{38}$ Ver en: arcas.fahce.unlp.edu.ar/greenstone3/sites/localsite/collect/puig/index/assoc/puigNBpN/B020033-.dir/boquitaspintadas0041r.jpg
} 
de lo sucedido en esos distintos lugares en determinadas fechas y horas", "relatos impersonales", o "descripción colección fotos”. Algunas de estas ideas se aplican en la novela, por ejemplo, la descripción minuciosa de las acciones realizadas por los personajes durante todo un día se emplea en la cuarta entrega, cuando se relatan las actividades desarrolladas por Nené y Juan Carlos el 23 de abril de 1937, ${ }^{39}$ y también en la quinta cuando se detallan las tareas efectuadas por Mabel, Pancho y Rabadilla. ${ }^{40}$ También se apunta "descripción colección fotos", sección que se desarrolla en la tercera entrega, en el "Álbum de fotografías", donde se brinda información de los personajes a través de las imágenes de un álbum de Juan Carlos. ${ }^{41}$ Hay otras indicaciones metaescriturarias sobre la técnica que no serán llevadas a cabo tal como se apuntan, por ejemplo, "trozos escritos por objetos [...] (banco, plaza, butaca, cine, mesa, club)", que sugiere una forma de escritura en la que el relato estaría a cargo de los objetos, como si fueran testigos de los acontecimientos (“descripción objetiva de los sucedido en esos distintos lugares en determinadas fechas y horas").

Como síntesis de las ideas expuestas en esta sección se comprende que en este proyecto creativo Puig se esfuerza por objetivar el relato ensayando distintas técnicas y por el programa estructural de la novela con la finalidad de dar solidez y coherencia a la forma, plan complejo que también supone un trabajo riguroso sobre la representación del tiempo y la trama, como se expondrá seguidamente.

${ }^{39}$ Por ejemplo: "El día jueves 23 de abril de 1937 el sol salió a las 5:50. Soplaban vientos leves de norte a sur, el cielo estaba parcialmente nublado y la temperatura era de 14 grados centígrados. Nélida Enriqueta Fernández durmió hasta las 7:45, hora en que su madre la despertó. Nélida tenía el pelo dividido en mechones atados con tiras de papel, mantenidos en su lugar por una redecilla negra que ceñía el cráneo entero" (50).

${ }^{40}$ Ejemplo: "El ya mencionad jueves 23 de abril de 1937, María Mabel Sáenz, conocida por todos como Mabel, abrió los ojos a las 7:00 de la mañana cuando su reloj despertador de marca suiza sonó la alarma. No pudo mantenerlos abiertos y volvió a quedarse dormida. A las 7:15 la cocinera golpeó a su puerta y le dijo que el desayuno estaba servido" (66).

${ }^{41}$ Ejemplo: "Primera fotografía grande de la derecha; niño de meses desnudo, rubio. Segundo grupo de la izquierda: un hombre y una mujer, él viste traje con chaleco y levita y ella ropa oscura larga hasta los pies, la misma pareja con dos niños en brazos, tres poses de la mujer del traje largo con dos ancianos y dos niños" (36). 
CATEDRAL TOMADA: Revista de crítica literaria latinoamericana / Journal of Latin American Literary Criticism Boquitas pintadas, una novela para armar. Primeras notas y borradores de un proyecto creativo en construcción

\section{Sobre el tiempo y la trama: ajustes para un programa cohesivo}

Otro caso singular corresponde a un cuadro en el que se considera el manejo narrativo del tiempo (N.B.1.0003r). ${ }^{42}$ En orden cronológico se organizan los acontecimientos esenciales para cada uno de los personajes, muchos de los cuales conservan todavía los nombres primitivos, como Pela (Rabadilla) y Danilo (Juan Carlos). En la columna de la izquierda se ingresan sus iniciales y en la fila superior los años que van desde 1935 hasta 1945, con algunos intervalos temporales. De la lectura del cuadro se deduce que la mayor parte de los acontecimientos que se producen entre 1935 y 1938 quedan en la novela de acuerdo con lo que se apunta en el bosquejo. En la línea de Nené, el baile de la primavera de 1936, la ruptura de su relación con Juan Carlos, por lo menos después de septiembre de 1937, cuando el muchacho regresa de la ciudad de Cosquín, en la provincia de Córdoba, y su casamiento con el señor Massa en 1938 coinciden con el plan esquematizado. Lo mismo ocurre en la fila de Juan Carlos con su regreso de la estadía en la localidad cordobesa, que sucede entre mayo y septiembre de 1937. En lo que respecta a Mabel, la fotografía que esconde en su cuarto, con una dedicatoria de Juan Carlos, que revela su primera relación sexual el 21 de septiembre de 1935 también coincide con lo proyectado en el cuadro. Así también, la pelea que mantiene con Juan Carlos en el año 1936 coincide con la celebración argentina del 25 de mayo, fecha en que el estanciero Cecil invita a la familia a pasar un día de campo. También concuerda la relación secreta que mantiene con Juan Carlos recibiéndolo en su habitación en 1937. Por su parte, Rabadilla es madre en enero de 1938 en consonancia con lo que se inscribe en el bosquejo.

No sucede lo mismo con los acontecimientos que ocurren después de 1938 según lo que revela el manuscrito, ya que las modificaciones operadas en el trasvase a la textualización son numerosas. Pueden contarse los diálogos telefónicos que Nené mantiene con Rabadilla en Buenos Aires, que acontecen en el año 1939, en

\footnotetext{
${ }^{42}$ Ver en: arcas.fahce.unlp.edu.ar/greenstone3/sites/localsite/collect/puig/index/assoc/puigNBpN/B010001-.dir/boquitaspintadas0003r.jpg
} 
lugar de 1940 como se bosqueja en el cuadro. El nacimiento del primer hijo de Nené ocurre después de esas conversaciones y no antes como se planea. La muerte de Juan Carlos se produce en 1947, a diferencia del año 1945 que arroja el manuscrito. La visita de Mabel a Nené ocurre en 1941, en lugar de lo planificado para 1944, por lo cual sólo se encuentra casada la segunda de las mujeres, en contraste con lo que proyecta el borrador, según el cual ambas estarían en matrimonio. De hecho, la confesión de Mabel ante el sacerdote ocurre después del encuentro con su antagonista, a diferencia de lo que muestra el testimonio escrito, y tiene por objeto limpiar sus pecados antes de la boda. La muerte de Pancho ocurre en 1939, y no en 1941 como se planea, por eso también se ajustan para ese mismo año los tangos interpretados por Libertad Lamarque que canta Rabadilla y generan sus dudas sobre la fidelidad del policía para luego corroborar la traición y cobrar venganza.

Las operaciones detalladas conducen a pensar, por un lado, en la necesidad de dar un orden gráfico al trabajo sobre la representación del tiempo en una novela que lo complejiza con constantes quiebres y rupturas en la lógica del relato. En la trama deben coincidir las partes de una historia que se narra en fragmentos, microestructuras de un rompecabezas que debe acoplarse y encastrar. Por otro lado, llama la atención que la primera mitad de lo planificado en el esquema coincide con respecto al desarrollo temporal de la novela publicada. En cambio, lo representado a partir de 1939, es decir, la segunda mitad de los acontecimientos del borrador tendrán variaciones y ajustes orientados a cohesionar el tiempo. Esto podría dar la pauta nuevamente de que la primera mitad de la novela se encuentra avanzada o, por lo menos, decidida con más firmeza al momento de realizar este tipo de bosquejos.

Lo mismo puede decirse del documento N.B.1.0002 $\mathrm{r}^{43}$ en el cual se apunta una estructura para la novela dividida en dieciocho capítulos, en lugar de los dieciséis que posee finalmente. Como se puede observar en el testimonio, los siete primeros de ellos no se encuentran en estado de planificación como el resto, sino

\footnotetext{
${ }^{43}$ Ver en: arcas.fahce.unlp.edu.ar/greenstone3/sites/localsite/collect/puig/index/assoc/puigNBpN/B010001-.dir/boquitaspintadas0002r.jpg
} 
CATEDRAL TOMADA: Revista de crítica literaria latinoamericana / Journal of Latin American Literary Criticism Boquitas pintadas, una novela para armar. Primeras notas y borradores de un proyecto creativo en construcción

que llevan la indicación "OK” en señal de que han sido concluidos y evaluados positivamente. El resto de las entregas se encuentra en estado de esbozo, con más detalles respecto de lo que se podía ver en testimonios analizados anteriormente, pero aún en estado de composición con anotaciones sobre los géneros discursivos y tipos textuales que les van a dar forma ("dialoguitos", "cartas", "archivo policía", "plegarias", "bolero"), con apuntes sobre acontecimientos o episodios, y sobre el trayecto de los personajes ("Pancho en La Plata", "tapial", "Raba Líber", "conversación viuda con Selina", "cerrar trayectoria Raba", "cerrar trayectoria Mila", “viaje a ver a Cosquín”, "última voluntad”).

Una última observación sobre este testimonio merece el proyecto de la novela en dieciocho capítulos, en lugar de los dieciséis finalmente adoptados. En este programa, las dos últimas entregas habían sido pensadas como un interludio y un epílogo. El primero desarrollaba lo que finalmente se relata en la entrega quince, es decir, la separación de Nené y su esposo, el viaje a Cosquín para encontrarse con la viuda Elsa di Carlo y el monólogo interior con alusiones a los boleros que la conducen a pensar en un posible encuentro con Juan Carlos. El epílogo respondía a lo que finalmente se relata en la entrega decimosexta, la muerte de Nené, su última voluntad y la incineración de las cartas.

\section{Consideraciones finales sobre la planificación inicial y ajustes de composición para Boquitas Pintadas:}

Para finalizar, el análisis nos permite extraer las siguientes reflexiones y observaciones. En principio, que los pre-textos prerredaccionales más representativos del proceso de escritura de Boquitas Pintadas son testimonios clave de un plan de obra razonado con un argumento inicial definido que el autor pule y complejiza en el proceso de redacción. Los esquemas, cuadros y bosquejos inscriptos en esos documentos permiten visualizar las distintas piezas discursivas que se programan y cómo se (re)organizan, cambian e intercambian esas partes en 
la macroestructura, cómo la trama profunda conecta las relaciones existentes entre los distintos personajes y sus roles, y cómo el tiempo representado como quebrado y roto se fractura en un momento particular y se (re)ajusta en la composición para no perder coherencia y lógica. En la estructura subterránea de la novela, que se revela en esos testimonios, también persisten huellas de referentes biográficos, de personajes inicialmente estereotipados, del producto de investigación de fuentes que se consultan o se consideran, todo un conjunto de materiales que se elaboran y modelan para construir una trama de relaciones que enlaza distintos tipos discursivos y dispositivos textuales como soportes de sus voces y de los tejidos que las conectan.

En cuanto a los criterios que guían la forma de la obra, se ha puesto de manifiesto el trazado de un plan estructural en la conjunción y reunión de esos objetos textuales como pilares y sostenes materiales y simbólicos que apuntan a la verosimilitud del relato a través de la objetividad, el trabajo con la ruptura cronológica y la búsqueda de coherencia para dar continuidad en el nivel del discurso a las escenas y episodios dispersos.

Los testimonios analizados también permiten clarificar la materia de la que se extrae el contenido para un relato de novela y el modo en que se va ajustando a los fines de un plan de ficcionalización con recursos de producción discursiva y manejo narrativo de toda índole, a través de distintos procedimientos como lo son el borramiento de las características del referente, los cambios en los nombres o la yuxtaposición y la combinación de distintas figuras. Esto se manifiesta concretamente en la inspiración para un personaje de una actriz-cantante argentina como lo es Libertad Lamarque, para el caso de Rabadilla; en la condensación de dos referentes que permanecen en el recuerdo de un suceso de la infancia, para el caso de Juan Carlos; o en la síntesis que hacen varios de ellos para dar con una imagen única, signo de violencia y muerte, como lo es el policía Pancho.

Por otro lado, este modo de trabajo ordenado, producto también de una investigación e indagación de fuentes, con un plan consciente de composición ya había sido estudiado en otros procesos escriturales de Manuel Puig, como en El 
CATEDRAL TOMADA: Revista de crítica literaria latinoamericana / Journal of Latin American Literary Criticism Boquitas pintadas, una novela para armar. Primeras notas y borradores de un proyecto creativo en construcción

beso de la mujer araña (1976), cuyo desarrollo de génesis puede consultarse en la edición crítica y genética de la Colección Archivos (2002). No obstante, quisimos comprobar cómo Boquitas pintadas funda ese modo de escritura y realización que será sostenido en trabajos posteriores, como el mencionado, y en su poética creativa en general. Analizamos entonces cómo ese modo complejo de producción textual parte de una escritura fundada en modelos realistas, estereotipados, referenciales y experimenta con la escritura para distanciarse cada vez más de la narrativa de tipo tradicional. Toda esa estructura, capa primaria y original queda documentada en los testimonios de prerredacción, así como también el interés por lograr una macroestructura compleja pero sólida, quebrada pero coherente.

Resta decir que este estudio centrado en los pre-textos prerredaccionales podría complementarse con un trabajo que aborde el desarrollo creativo en la etapa redaccional de Boquitas pintadas con el objeto de articular los resultados de las dos instancias y ampliar el panorama de la investigación sobre el proceso de composición de esta novela fundamental de la literatura argentina, tarea que no desestimamos para un proyecto futuro.

\section{Bibliografía}

Colla, Fernando. "Génesis de un objeto (de estudio)". Escribas, monjes, filólogos, ordenadores. La preservación de la memoria escrita en Occidente.

Córdoba: Alción, 2010, pp. 303-337.

De Biasi, Pierre-Marc. “¿Qué es un borrador? El caso Flaubert: ensayo de tipología funcional de los documentos de génesis”. Genética textual. Introducción, compilación de textos y bibliografía de Emilio Pastor Platero, Madrid: Arco Libros, 2008, pp. 113-151. 
CATEDRAL TOMADA: Revista literaria latinoamericana / Journal of Latin American Literary Criticism Giselle Carolina Rodas

De Biasi, Pierre-Marc. La Génétique des textes. Nathan, París, 2003.

Giordano, Alberto. "Manuel Puig: los comienzos de una literatura menor". Orbis Tertius, 1, n 2-3, 1996, pp. 255-274.

. "Boquitas pintadas o los usos del imaginario sentimental". La conversación infinita, Rosario: Beatriz Viterbo, 2001, pp. 115-140.

Grésillon, Almuth. Éléments de critique génétique. Lire les manuscrits modernes, París : Presses Universitaires de France, 1994. . «Qué es la crítica genética». Filología. Volumen dedicado a Crítica Genética a cargo de Élida Lois. Año XXVII, 1-2, 1994, pp. 25-52.

Lavers, Norman. Pop Culture Into Art: The Novels of Manuel Puig. Columbia, University of Missouri Press, 1988.

Lois, Élida. Génesis de escritura y estudios culturales. Introducción a la crítica genética. Buenos Aires, Edicial, 2001.

Lorenzo- Alcalá, May. “Apuntes para una estética pop. (Sobre las tres primeras novelas de Manuel Puig)". América Hispânica. Homenagem a Manuel Puig (1932-1990), SEPEHA, Faculdade de Letras, III, 4, jul. / dez., 1990, pp. 93 98.

Ludmer, Iris Josefina. “Boquitas Pintadas. Siete recorridos”. Actual. Revista de la Universidad de los Andes, 8-9, enero-diciembre, 1971, pp. 3-22.

Páez, Roxana. “Una novela pop”. Manuel Puig. Del pop a la extrañeza, Buenos Aires, Almagesto, 1995, pp. 11-50.

Puig, Manuel. “Colección Manuel Puig”. Organización, clasificación y comentario: Graciela Goldchluk. Arcas. arcas.fahce.unlp.edu.ar/arcas/portada/colecciones/manuel-puig . "Prólogo". La cara del villano. Recuerdo de Tijuana. Barcelona, Seix Barral, 1985, pp. 7-14. . Boquitas pintadas. Folletín. Buenos Aires, Sudamericana, 1969. . El beso de la mujer araña. Edición crítica. José Amícola y Jorge Panesi (coord.). Colección Archivos, nº 42. Madrid: ALLCA XX, 2002. . La traición de Rita Hayworth. Buenos Aires, Jorge Alvarez, 1968. 
CATEDRAL TOMADA: Revista de crítica literaria latinoamericana / Journal of Latin American Literary Criticism Boquitas pintadas, una novela para armar. Primeras notas y borradores de un proyecto creativo en construcción

. Querida familia. Tomo 1: Cartas europeas (1956-1962). Graciela

Goldchluk (comp.). Buenos Aires, Entropía, 2005.

. Querida familia. Tomo 2: Cartas americanas (1963-1983). Graciela

Goldchluk (comp.). Buenos Aires, Entropía, 2006.

Rodas, Giselle. "Escrituras y reescrituras en torno al tango en Boquitas pintadas.

Folletín de Manuel Puig”. Libro de Actas del Congreso Regional de la

Cátedra UNESCO en Lectura y Escritura. Cultura Escrita y Políticas

Pedagógicas en las Sociedades Latinoamericanas Actuales. Susana

Nothstein, María Cecilia Pereira y Elena Valente (Comps.), Los

Polvorines: Instituto del Desarrollo Humano y la Especialización en

\section{Prácticas Sociales de Lectura y Escritura, Universidad Nacional de General}

Sarmiento, 2012, pp. 594- 604.

. Edición crítico-genética de Boquitas pintadas. Folletín (1969), de

Manuel Puig. Tesis doctoral defendida el 11 de junio de 2015. Facultad de

Humanidades y Ciencias de la Educación, UNLP. Inédito.

. "Había en tus ojeras la inconfundible huella que hablaba de tu mal".

Pálido final para Juan Carlos y comienzo para Boquitas pintadas". El hilo

de la fábula, 11, 2011, 129-139. Disponible en:

bibliotecavirtual.unl.edu.ar/ojs/index.php/HilodelaFabula/article/view/1972/ 2998

. "La construcción de un 'Dormitorio de señorita' como antesala de un

caso: tercera y undécima entregas de Boquitas pintadas. Folletín". Recto

Verso. Revue de jeunes chercheurs en critique génétique, № 7, 2011.

www.revuerectoverso.com/spip.php?article203

Rodríguez Monegal, Emir. "El folletín rescatado: entrevista a Manuel Puig". Julia

Romero (comp.). Puig por Puig. Imágenes de un escritor, Madrid:

Iberoamericana- Vervuert, 2006, pp. 54-58.

Sosnowski, Saúl. "Manuel Puig: entrevista". Hispamérica: Revista de Literatura, 3, 1973, pp. 69-80. 
CATEDRAL Tomada: Revista literaria latinoamericana / Journal of Latin American Literary Criticism Giselle Carolina Rodas

Speranza, Graciela. Manuel Puig. Después del fin de la literatura, Buenos Aires:

Norma, 2003. 